\title{
Air pollution, fetal and infant tobacco smoke exposure, and wheezing in preschool children: a population-based prospective birth cohort
}

\author{
Agnes MM Sonnenschein-van der Voort ${ }^{1,2,3}$, Yvonne de Kluizenaar ${ }^{4}$, Vincent W Jaddoe ${ }^{1,3,5}$, Carmelo Gabriele ${ }^{1,2,6}$, \\ Hein Raat ${ }^{7}$, Henriëtte A Moll ${ }^{5}$, Albert Hofman ${ }^{3}$, Frank H Pierik ${ }^{4}$, Henk ME Miedema ${ }^{4}$, Johan C de Jongste ${ }^{2}$ \\ and Liesbeth Duijts $2,3,8^{*}$
}

\begin{abstract}
Background: Air pollution is associated with asthma exacerbations. We examined the associations of exposure to ambient particulate matter $\left(\mathrm{PM}_{10}\right)$ and nitrogen dioxide $\left(\mathrm{NO}_{2}\right)$ with the risk of wheezing in preschool children, and assessed whether these associations were modified by tobacco smoke exposure.

Methods: This study was embedded in the Generation R Study, a population-based prospective cohort study among 4,634 children. $\mathrm{PM}_{10}$ and $\mathrm{NO}_{2}$ levels were estimated for the home addresses using dispersion modeling. Annual parental reports of wheezing until the age of 3 years and fetal and infant tobacco smoke exposure was obtained by questionnaires.

Results: Average annual $\mathrm{PM}_{10}$ or $\mathrm{NO}_{2}$ exposure levels per year were not associated with wheezing in the same year. Longitudinal analyses revealed non-significant tendencies towards positive associations of $\mathrm{PM}_{10}$ Or $\mathrm{NO}_{2}$ exposure levels with wheezing during the first 3 years of life (overall odds ratios ( $95 \%$ confidence interval): 1.21 $(0.79,1.87)$ and $1.06(0.92,1.22))$ per $10 \mu \mathrm{g} / \mathrm{m}^{3}$ increase $\mathrm{PM}_{10}$ and $\mathrm{NO}_{2}$, respectively). Stratified analyses showed that the associations were stronger and only significant among children who were exposed to both fetal and infant tobacco smoke (overall odds ratios $4.54(1.17,17.65)$ and $1.85(1.15,2.96))$ per $10 \mu \mathrm{g} / \mathrm{m}^{3}$ increase $\mathrm{PM}_{10}$ and $\mathrm{NO}_{2}$, respectively ( $p$-value for interactions $<0.05$ ).
\end{abstract}

Conclusions: Our results suggest that long term exposure to traffic-related air pollutants is associated with increased risks of wheezing in children exposed to tobacco smoke in fetal life and infancy. Smoke exposure in early life might lead to increased vulnerability of the lungs to air pollution.

Keywords: Cohort study, Asthma, Pediatrics, Environmental tobacco smoke exposure, Air pollution

\section{Background}

Higher exposure levels to air pollutants have been associated with increased risks of asthma exacerbations in adults and children aged older than 5 years [1-5]. The influence of air pollution on asthma and wheezing in younger children is less clear [6-9]. The effects of air pollutants on airway symptoms may differ between children and adults. Children older than 6 months of age may breathe more

\footnotetext{
* Correspondence: I.duijts@erasmusmc.nl

${ }^{2}$ Department of Pediatrics, Division of Respiratory Medicine, Erasmus Medical Center, Rotterdam, The Netherlands

${ }^{3}$ Department of Epidemiology, Erasmus Medical Center, Rotterdam, The Netherlands

Full list of author information is available at the end of the article
}

through the mouth than adults, and benefit less from the filtering, humidifying and temperature raising effect of the nose and might therefore inhale higher air pollutants levels [10]. Also, children spend more time outdoors than adults, and have a larger ratio of lung surface area to body weight $[7,10,11]$, leading to a potential stronger effect of air pollution on airway symptoms, including wheezing [12]. A limited number of prospective birth cohort studies suggested associations of exposure to traffic-related air pollution, including particulate matter $\left(\mathrm{PM}_{10}\right)$ and nitrogen dioxide $\left(\mathrm{NO}_{2}\right)$, and the risk of wheezing and asthma in children up to the age of 8 years $[8,9,13,14]$. Thus far, results seem inconsistent [6]. This might be due to differences in study 
design, exposure and outcome assessment or confounding due to socio-demographic variables or a family history of asthma. Like some other environmental exposures, fetal and infant tobacco smoke exposure negatively influence the risk of asthma symptoms in early childhood, and might increase the susceptibility for the adverse effects of air pollution [15]. Therefore the associations between air pollution and asthma symptoms may be modified by tobacco smoke exposure [3].

We examined the associations of exposure to trafficrelated air pollutants $\mathrm{PM}_{10}$ and $\mathrm{NO}_{2}$, during different exposure windows, with the risk of wheezing in preschool children in a prospective birth cohort study among 4,634 children living in the city of Rotterdam, The Netherlands. In addition, we assessed whether fetal or infant tobacco smoke exposure modified these associations.

\section{Methods}

\section{Design and setting}

This study was embedded in the Generation R Study, a prospective cohort study from early fetal life to young adulthood in Rotterdam in the Netherlands [16]. The study protocol was approved by the Medical Ethical Committee of the Erasmus Medical Centre, Rotterdam. Written informed consent was obtained from all participants. In total 7,295 children born between 2002 and 2006 and their parents participated in the postnatal phase of the study. Of all eligible children in the study area, $61 \%$ participated in the present study. We excluded twins $(n=179), 2^{\text {nd }}$ and $3^{\text {rd }}$ pregnancies in the study $(\mathrm{n}=539)$ and children of whom we did not receive any questionnaire $(n=996)$. Of the remaining children $(n=5,581)$ valid air pollution data were available for 4,937 children (Figure 1). Air pollution exposure could not be assessed for 644 children, due to incomplete address history, moving outside the study area or invalid measurements. We excluded children without any information about wheezing ( $\mathrm{n}=303$ subjects). The final study population for analysis consisted of 4,634 children.

\section{Traffic-related air pollution exposure}

Individual child exposures levels to particulate matter $\left(\mathrm{PM}_{10}\right)$ and nitrogen dioxide $\left(\mathrm{NO}_{2}\right)$ were assessed at the

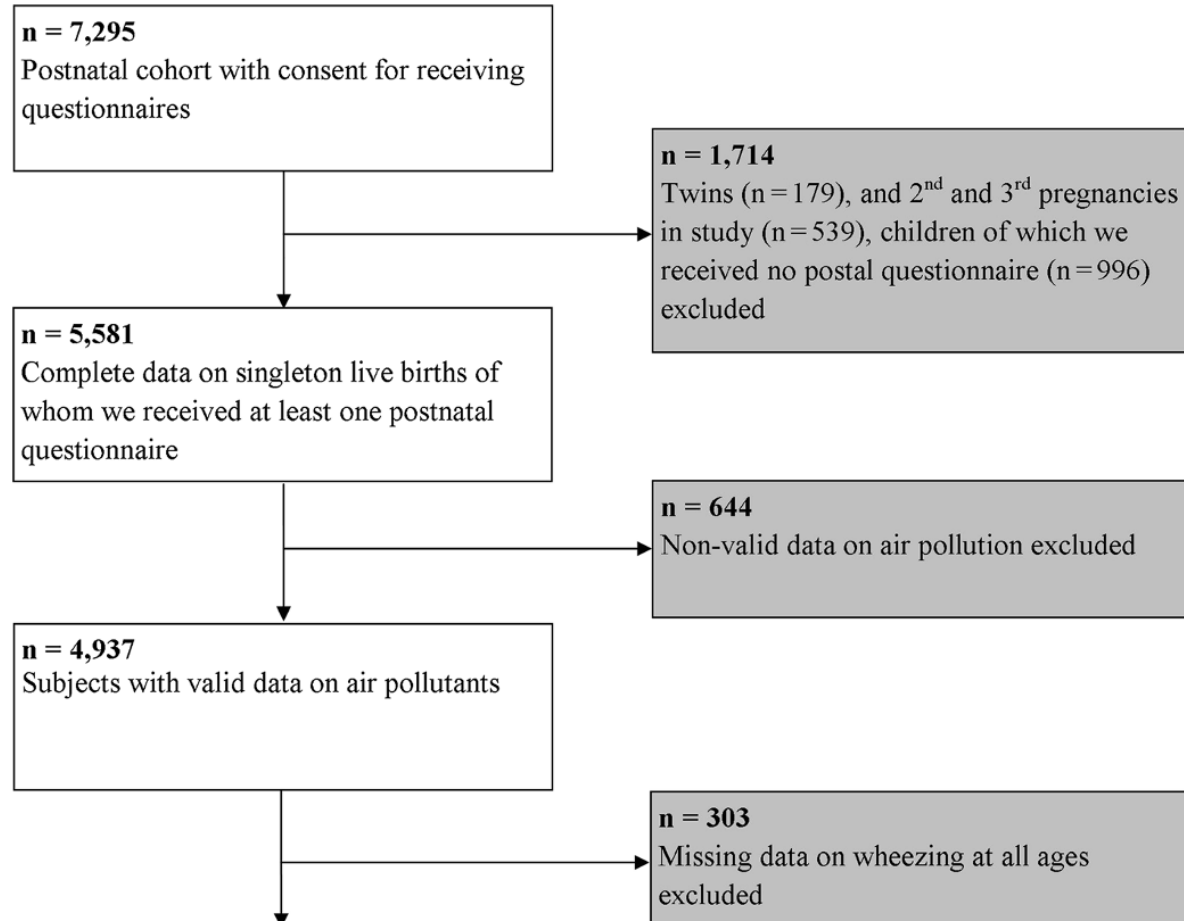

$\mathrm{n}=\mathbf{4 , 6 3 4}$

Subject with any data on wheezing

Age 1: $\mathrm{n}=3,950$

Age 2: $n=4,089$

Age 3: $n=3,838$

Figure 1 Flow chart of participants in study. 
home address, using a combination of continuous monitoring and dispersion modeling, taking into account both the spatial and temporal variation in air pollution. The exposure assessment has been described in detail previously [17]. Briefly, annual average concentrations of $\mathrm{PM}_{10}$ and $\mathrm{NO}_{2}$ for the years 2002-2008 were assessed for all addresses in the study area. This was done using the 3 Dutch national standard methods for air quality modeling, designated to calculate the contribution of different air pollution sources [18]. Subsequently, hourly concentrations of $\mathrm{PM}_{10}$ and $\mathrm{NO}_{2}$ were derived, using air pollution measurements from 3 continuous monitoring stations (hourly calibration), taking into account wind conditions and fixed temporal patterns in source contributions. Based on participants' home addresses, we derived individual exposure estimates for different periods during the first 3 years of life, including average exposure to air pollutants annually and overall. Average exposures were calculated for periods with $<20 \%$ of the concentrations missing. For the other periods, air pollution exposures were set to missing. The performance of this model has been evaluated by two studies in the same study area which show a good agreement between predicted annual average $\mathrm{PM}_{10}$ and $\mathrm{NO}_{2}$ concentrations, and concentrations measured at monitoring stations $[19,20]$.

\section{Respiratory symptoms}

Information on wheezing ("Has your child had problems with a wheezing chest during the last year ?" no; yes) was obtained by questionnaires at the ages of 1,2 and 3 years. Questions were adapted from the International Study on Asthma and Allergy in Childhood (ISAAC) [21]. Response rates for these questionnaires were $71 \%, 76 \%$ and $72 \%$, respectively [22].

\section{Covariates}

Information on maternal educational level, parity, smoking habits, smoking habits of the partner, history of asthma or atopy, children's ethnicity and pet keeping were obtained by a questionnaire at enrolment. We used parity as a proxy for siblings (correlation: kappa $=0.894$ ). Fetal smoke exposure was defined using data of maternal smoking habits during first, second and third trimester of pregnancy collected by questionnaires. We categorised groups as those children who were never exposed to tobacco smoke or in first trimester only (no fetal smoke exposure) and those who were continuously exposed to tobacco smoke in trimesters thereafter (fetal smoke exposure) [15]. Infant smoke exposure was defined as exposure to household tobacco smoke by anyone at the age of 2 years of the child (no; yes, data collected by questionnaires). Sex, gestational age at birth and birth weight of the children were obtained from midwife and hospital registries at birth. Postal questionnaires sent at the ages of 6 and 12 months provided information about breastfeeding. A questionnaire sent at the age of 12 months provided information on daycare attendance. Questionnaires filled in by the parents at the ages of 1, 2 and 3 years provided information about doctor attended lower respiratory tract infections (Has your child had pertussis, bronchitis, bronchiolitis or pneumonia in the past year for which a doctor or hospital was attended? no; yes) $[16,22]$.

\section{Statistical analysis}

We used multiple logistic regression models to analyze the associations of exposure to air pollution in the previous year with the risks of wheezing at the ages of 1,2 and 3 years. With Generalized Estimating Equation (GEE) analyses, we were able to take the correlation between repeated measurements in the same subject into account, and to calculate the overall effect (average air pollution levels in the first 3 years of life with wheezing at age 1 to 3 years combined). We used a compound symmetry corrlation matrix in these models. All models were adjusted for potential confounders including maternal age, education, parity, smoking habits during pregnancy, smoking habits of the partner, history of asthma or atopy, and children's sex, gestational age at birth, birth weight, ethnicity, breastfeeding status, daycare attendance, pet keeping and lower respiratory tract infections. Average exposures to $\mathrm{PM}_{10}$ and $\mathrm{NO}_{2}$, annually and overall, were analyzed as continuous variables and as quartiles (lowest quartile as the reference group). Tests for trend were performed by including average air pollutant concentration levels as continuous variables into the fully adjusted logistic regression model and we calculated the risk per $10 \mu \mathrm{g} / \mathrm{m}^{3}$ increase. Next, we stratified our models for tobacco smoke exposure to assess whether any observed association of air pollution with childhood wheezing was modified by environmental tobacco smoke exposure. For this analysis we also tested the interaction between air pollution and environmental tobacco smoke exposure. The tobacco smoke variables were combined into a new variable with 4 early smoke exposure categories: never; only fetal; only infant; and fetal and infant, using the variables about maternal smoking habits during pregnancy (fetal smoke exposure) and exposure to household tobacco smoke at the age of 2 years (infant smoke exposure). We performed multiple imputations to handle missing values of the covariates and outcomes by generating 25 independent datasets [23]. We imputed both covariates and outcomes, as missing values may introduce bias in GEE models [24]. Imputations were based on the relationships between all covariates and outcomes included in this study plus paternal age, educational level, history of asthma or atopy and information about shortness of breath in the past year of the children at the age of 1, 2 and 3 years. All datasets were analyzed separately after which results were combined. No differences 
in results were observed between analyses with imputed missing data or complete cases only. We only present results based on imputed datasets. All measures of association are presented with their 95\% confidence intervals (CI). Statistical analyses were performed using the Statistical Package of Social Sciences version 17.0 for Windows (SPSS Inc., Chicago, IL, USA) and SAS 9.2 (SAS institute, Cary, NC, USA).

\section{Results and discussion}

\section{Subject characteristics}

Children were born at a median gestational age of 39.9 (5-95\% range: 37.0-42.1) weeks with a mean birth weight of 3,439 (SD 556) grams (Table 1). Of all children who were exposed to tobacco smoke during fetal life, $59.3 \%$ was exposed to household tobacco smoke in infancy, whereas of all children who were not exposed to tobacco smoke during fetal life, $12.2 \%$ was exposed to household tobacco smoke in infancy. (Additional file 1: Table S1). The wheezing prevalence declined with increasing age. Mean annual $\mathrm{PM}_{10}$ levels were 28.9, 28.3 and 27.9 $\mu \mathrm{g} / \mathrm{m}^{3}$ and mean annual $\mathrm{NO}_{2}$ levels were 38.7, 37.5 and $36.2 \mu \mathrm{g} / \mathrm{m}^{3}$ at the ages of 1,2 and 3 years, respectively (Additional file 1: Table S2).

\section{Air pollution and risk of wheezing}

We observed no associations of average $\mathrm{PM}_{10}$ and $\mathrm{NO}_{2}$ concentrations during the previous year with the risks of wheezing at the ages of 1,2 or 3 years separately or in the overall longitudinal model (Table 2). Additional analyses showed that children exposed to the highest $25 \% \mathrm{PM}_{10}$ and $\mathrm{NO}_{2}$ levels did not have an increased risk of wheezing in the first 3 years compared to those exposed to the lowest $25 \%$ air pollutants levels (results not shown). At the age of 1 year only, information about the average exposure to air pollutants and wheezing during the last month was available. As compared to the average per year exposure we observed a larger variation in exposure levels of air pollutants measured in the previous month at the age 1 year (Additional file 1: Table S2). Furthermore, exposure to increased levels of $\mathrm{PM}_{10}$ during the previous month tended to be associated with an elevated risk of wheezing but the effect estimate did not reach statistical significance (OR $1.25(0.98,1.58)$ per $\left.10 \mu \mathrm{g} / \mathrm{m}^{3}\right)$. Increased levels of $\mathrm{NO}_{2}$ during the previous month were associated with wheezing (OR $1.32(1.11,1.55)$ per $10 \mu \mathrm{g} / \mathrm{m}^{3}$ ) (Table 3). We observed no time-dependent effect of air pollutants on wheezing in the first 3 years ( $p$-values for interaction time*air pollutant: >0.05). We explored the confounding and modifying effect of lower respiratory tract infections and did not observe changes in our effect estimates after adjusting the analyses for lower respiratory tract infections. Also, the interaction between air pollution and lower respiratory tract infections was not significant, and we observed no associations between air pollutants and lower respiratory tract infections (data not shown).

\section{Air pollution, tobacco smoke exposure and risk of wheezing}

We found no associations of air pollutants levels with the annual risks of wheezing stratified for fetal and infant smoke exposure (Additional file 1: Table S3). Stratified longitudinal analyses showed that the associations of average $\mathrm{PM}_{10}$ and $\mathrm{NO}_{2}$ exposure levels with the overall longitudinal risks of wheezing during the first 3 years of life were stronger and significant among children who were exposed to tobacco smoke both during fetal and infant life (overall odds ratios 4.54 (1.17, 17.65) and $1.85(1.15,2.96)$ per $10 \mu \mathrm{g} / \mathrm{m}^{3}$ increase in $\mathrm{PM}_{10}$ and $\mathrm{NO}_{2}$, respectively) (Figure 2). We did not observe associations of traffic-related air pollutants with wheezing among children who were exposed to smoke during fetal life only or during infancy only. However, we observed elevated odds ratios for infant smoke exposure, but these effect estimates were not significant. We additionally assessed whether tobacco smoke exposure modified the association of air pollution with risks of wheezing by using interaction terms. These interaction terms were statistically significant for the associations of air pollutants with longitudinally measured wheezing (P-values for interaction: PM10*smoking: p-value <0.05; NO2*smoking: p-value <0.01). However, per year analyses showed that the association of air pollutants with wheezing was modified by tobacco smoke exposure only at the age of 3 years (P-values for interaction per year: $\mathrm{PM}_{10}$ *smoking: $\mathrm{p}$-value $=0.35$ (age 1), $\mathrm{p}$-value $=0.20$ (age 2), and p-value $<0.05$ (age 3). P-values for interaction $\mathrm{NO}_{2}{ }^{*}$ smoking are: $\mathrm{p}$-value $=0.23($ age 1$), \mathrm{p}$-value $=0.14($ age 2$)$, and $\mathrm{p}$-value $<0.05$ (age 3)).

\section{Discussion}

Our study suggests that long term exposure to higher levels of traffic-related air pollutants $\mathrm{PM}_{10}$ and $\mathrm{NO}_{2}$ are associated with increased risks of wheezing in the first 3 years of life among children who are exposed to tobacco smoke during fetal and infant life. We did not observe associations of traffic-related air pollutants with wheezing among children who were not exposed to tobacco smoke.

Previous studies reported inconsistent findings for the associations of traffic-related air pollution with asthma symptoms and doctor diagnosed asthma [6,7]. Associations of $\mathrm{NO}_{2}$ and $\mathrm{PM}_{2.5}$ with overall wheezing until the age of 8 years were observed in another study in the Netherlands [14]. A Swedish cohort study observed associations of air pollution in the first year of life with persistent wheezing until 4 years of age [25]. A study in Germany observed no associations of long term exposure to $\mathrm{PM}_{2.5}$ or $\mathrm{NO}_{2}$ with the risks of parental reports of asthma symptoms, but 
Table 1 Maternal and child characteristics

$\frac{n=4,634}{$\cline { 2 - 3 } \text {$Observed } \begin{array}{c}\text { After multiple } \\ \text { imputations }\end{array}}$

Maternal characteristics

Age (years)*

Highest completed education (\%)

Non-completed, primary or secondary

Higher

Missing

Parity (\%)

Nulliparity
Multiparity
Missing

History of asthma or atopy (\%)

No
Missing

\section{Fetal and Child characteristics}

Male sex (\%)

Gestational age at birth (weeks)

Birth weight (grams)*

Ethnicity (\%)

European
Non-European
Missing

Breastfed (\%)

No
Yes
Missing

Day care attendance (\%)

No
Yes
Missing

Pet keeping (\%)

$\begin{array}{lcc}\text { No } & 65.5(2,399) & 64.6(2,993) \\ \text { Yes } & 34.5(1,263) & 35.4(1,641) \\ \text { Missing } & 21.0(972) & -\end{array}$

Lower respiratory tract infections age 1 year (\%)

No
Yes
Missing

Lower respiratory tract infections age 2 years (\%)

No

$$
\begin{array}{cc}
86.4(3,165) & 85.4(3,957) \\
13.6(498) & 14.6(677) \\
21.0(971) & -
\end{array}
$$

\begin{tabular}{|c|c|c|}
\hline Yes & $12.1(484)$ & $12.6(582)$ \\
\hline Missing & $14.2(659)$ & - \\
\hline \multicolumn{3}{|c|}{$\begin{array}{l}\text { Lower respiratory tract infections age } \\
3 \text { years (\%) }\end{array}$} \\
\hline No & $93.3(3,453)$ & $92.7(4,294)$ \\
\hline Yes & $6.7(247)$ & $7.3(340)$ \\
\hline Missing & $20.2(934)$ & - \\
\hline \multicolumn{3}{|c|}{ Smoking of father (\%) } \\
\hline No & $57.4(2,153)$ & $57.4(2,658)$ \\
\hline Yes & $42.6(1,599)$ & $42.6(1,976)$ \\
\hline Missing & $19.0(882)$ & - \\
\hline \multicolumn{3}{|c|}{ Fetal smoke exposure (\%) } \\
\hline No & $86.9(3,246)$ & $86.4(4003)$ \\
\hline Yes & $13.1(489)$ & $13.6(631)$ \\
\hline Missing & $19.4(899)$ & - \\
\hline \multicolumn{3}{|c|}{ Infant smoke exposure (\%) } \\
\hline No & $82.3(3,391)$ & $81.4(3,770)$ \\
\hline Yes & 17.7 (728) & $18.6(864)$ \\
\hline Missing & $11.1(515)$ & - \\
\hline \multicolumn{3}{|c|}{ Wheezing age 1 year (\%) } \\
\hline No & $74.0(2,922)$ & $74.1(3,433)$ \\
\hline Yes & $26.0(1,028)$ & $25.9(1,201)$ \\
\hline Missing & $14.8(684)$ & - \\
\hline \multicolumn{3}{|c|}{ Wheezing age 2 years (\%) } \\
\hline No & $82.1(3,358)$ & $82.6(3,827)$ \\
\hline Yes & $17.9(731)$ & $17.4(807)$ \\
\hline Missing & $11.8(545)$ & - \\
\hline \multicolumn{3}{|c|}{ Wheezing age 3 years (\%) } \\
\hline No & $89.0(3,417)$ & $89.4(4,143)$ \\
\hline Yes & $11.0(421)$ & $10.6(491)$ \\
\hline Missing & $17.2(796)$ & - \\
\hline
\end{tabular}

$87.9(3,494) \quad 87.4(4,052)$
Table 1 Maternal and child characteristics (Continued)

Values are percentages (absolute values), means (SD)* or medians $\left(5-95^{\text {th }}\right.$ percentile $)^{5}$.

Missing percentages are given for the total population of analysis $n=4634$.

Other percentages are valid percentages.

observed an association of $\mathrm{PM}_{2.5}$ exposure levels with doctor diagnosed asthma at the age of 6 years [26]. Finally, a large Canadian study reported inconsistent results for the associations of air pollutant levels with the risk of asthma until the age of 4 years, depending on the exposure assessment. The authors reported no association of traffic-related air pollution based on land use regression modeling with the risks of asthma, but reported associations of distance to industrial point sources with an increased risk of asthma [27]. Differences between our study and previous published studies include our detailed method to assess air pollution exposure levels in a large city, the availability of many 
Table 2 Exposure to air pollutants (previous year, overall) and risks of wheezing

\begin{tabular}{|c|c|c|c|c|}
\hline & & Odds ratio of wh & fidence Interva & \\
\hline & Age 1 year & Age 2 years & Age 3 years & Overall \\
\hline $\mathrm{PM}_{10}$ & & & & \\
\hline Crude & $1.07(0.77,1.50)$ & $1.54(0.90,2.61)$ & $1.00(0.51,1.95)$ & $1.28(0.85,1.91)$ \\
\hline Adjusted & $1.21(0.84,1.74)$ & $1.49(0.83,2.66)$ & $0.90(0.43,1.91)$ & $1.28(0.83,1.98)$ \\
\hline $\mathrm{NO}_{2}$ & & & & \\
\hline Crude & $1.01(0.85,1.20)$ & $1.04(0.85,1.27)$ & $1.03(0.79,1.33)$ & $1.05(0.92,1.19)$ \\
\hline Adjusted & $1.07(0.89,1.29)$ & $1.04(0.83,1.29)$ & $0.97(0.72,1.30)$ & $1.07(0.93,1.23)$ \\
\hline
\end{tabular}

potential confounders and the interaction with smoke exposure. Also, earlier studies did not use individual exposure levels [27], took only the birth addresses into account or were not able to adjust for home movement [9,14,25]. Children in our study were exposed to a smaller range of $\mathrm{NO}_{2}$ exposure (range 28.8-56.1 $\mu \mathrm{g} / \mathrm{m}^{3}$ ) as compared with another Dutch study $\left(\mathrm{NO}_{2}\right.$ range 12.6-58.4 $\left.\mu \mathrm{g} / \mathrm{m}^{3}\right)$ which might have led to smaller effect estimates [14]. By using long term exposure averages, the potential short term high risk exposure levels may be missed. At the age of 1 year only, we obtained information about wheezing in the last month and the average exposure to air pollutants during that month. Increased levels of air pollutants exposure during the previous 1 month were associated with increased

Table 3 Exposure to air pollutants in the previous month and wheezing in the same month

\begin{tabular}{|c|c|c|}
\hline & \multicolumn{2}{|c|}{$\begin{array}{l}\text { Odds ratio of wheezing in previous month age } 1 \text { year } \\
\qquad(95 \% \text { Confidence Interval) }\end{array}$} \\
\hline & $\begin{array}{c}\mathrm{PM}_{10} \\
\mathrm{n}=373\end{array}$ & $\begin{array}{c}\mathrm{NO}_{2} \\
\mathrm{n}=373\end{array}$ \\
\hline \multirow[t]{2}{*}{ Quartile 1} & Reference & Reference \\
\hline & $\mathrm{n}=83$ & $n=72$ \\
\hline \multirow[t]{2}{*}{ Quartile 2} & $1.24(0.90,1.71)$ & $1.28(0.91,1.79)$ \\
\hline & $n=97$ & $n=87$ \\
\hline \multirow[t]{2}{*}{ Quartile 3} & $1.08(0.77,1.49)$ & $1.54(1.11,2.13)^{*}$ \\
\hline & $n=82$ & $n=103$ \\
\hline \multirow[t]{2}{*}{ Quartile 4} & $1.38(1.01,1.88)^{*}$ & $1.62(1.17,2.24)^{* *}$ \\
\hline & $\mathrm{n}=111$ & $n=111$ \\
\hline \multirow[t]{2}{*}{ Trend } & $1.25(0.98,1.58)$ & $1.32(1.11,1.55)$ \\
\hline & $p=0.07$ & $p<0.01$ \\
\hline
\end{tabular}

Values are odds ratios (95\% confidence interval) for wheezing from logistic regression models. ${ }^{*} \mathrm{P}<0.05$ and ${ }^{* *} \mathrm{p}<0.01$. Models are adjusted for maternal age, education, parity, smoking, smoking of the partner, history of asthma or atopy and children's sex, gestational age, birth weight, ethnicity, breastfeeding, daycare attendance, pet keeping and lower respiratory tract infections at age 1 year. Trend represents the risk of wheezing per $10 \mu \mathrm{g} / \mathrm{m}^{3}$ increase in $\mathrm{PM}_{10}$ or $\mathrm{NO}_{2}$. risks of wheezing. We were not able to assess this short time interval at older ages.

We observed an interaction between air pollution and tobacco smoke exposure for the association with longitudinally measured wheezing. However, in our per year analyses we observed that this interaction was only significant at the age of 3 years. This might be explained by the idea that from the age of 3 years onwards wheezing represents another phenotype than earlier wheezing in which other factors such as atopic susceptibility in the origins of wheezing become more important. Also, infant smoke exposure was assessed after respiratory outcomes at age 1 year. This might be a reason for observing no significant interaction between exposure to air pollutants, tobacco smoke and wheezing before the age of 3 years. Our results suggest that tobacco smoke exposure increases the vulnerability of the lungs to air pollutants. The interaction between particulate matter and tobacco smoke exposure was previously explored by Rabinovitch et al. [3]. They observed that environmental tobacco smoke exposure modifies the acute effects of low-level ambient $\mathrm{PM}_{2.5}$ exposure on childhood asthma. Albuterol usage and leukotriene $\mathrm{E}_{4}$ were only related to $\mathrm{PM}_{2.5}$ concentrations on days when urine cotinine levels were low, which suggest that only when children were not or to a small amount exposed of tobacco smoke, exposure to air pollution was positively associated with asthma. Their results were in the opposite direction as compared to our results. This difference might be explained by differences in study design and methods. We assessed reported tobacco smoke exposure both in fetal and infant life, wheezing at younger ages, and long term exposure to tobacco smoke and air pollution. Rabinovitch et al. assessed biological markers of smoke exposure in childhood, used albuterol usage as a proxy for asthma, at an older age, and assessed the short term effects of air pollutants. Previous studies suggested that both short term and long term exposure to air pollutants are important for the development of asthma exacerbations or respiratory symptoms [25,28-34]. 


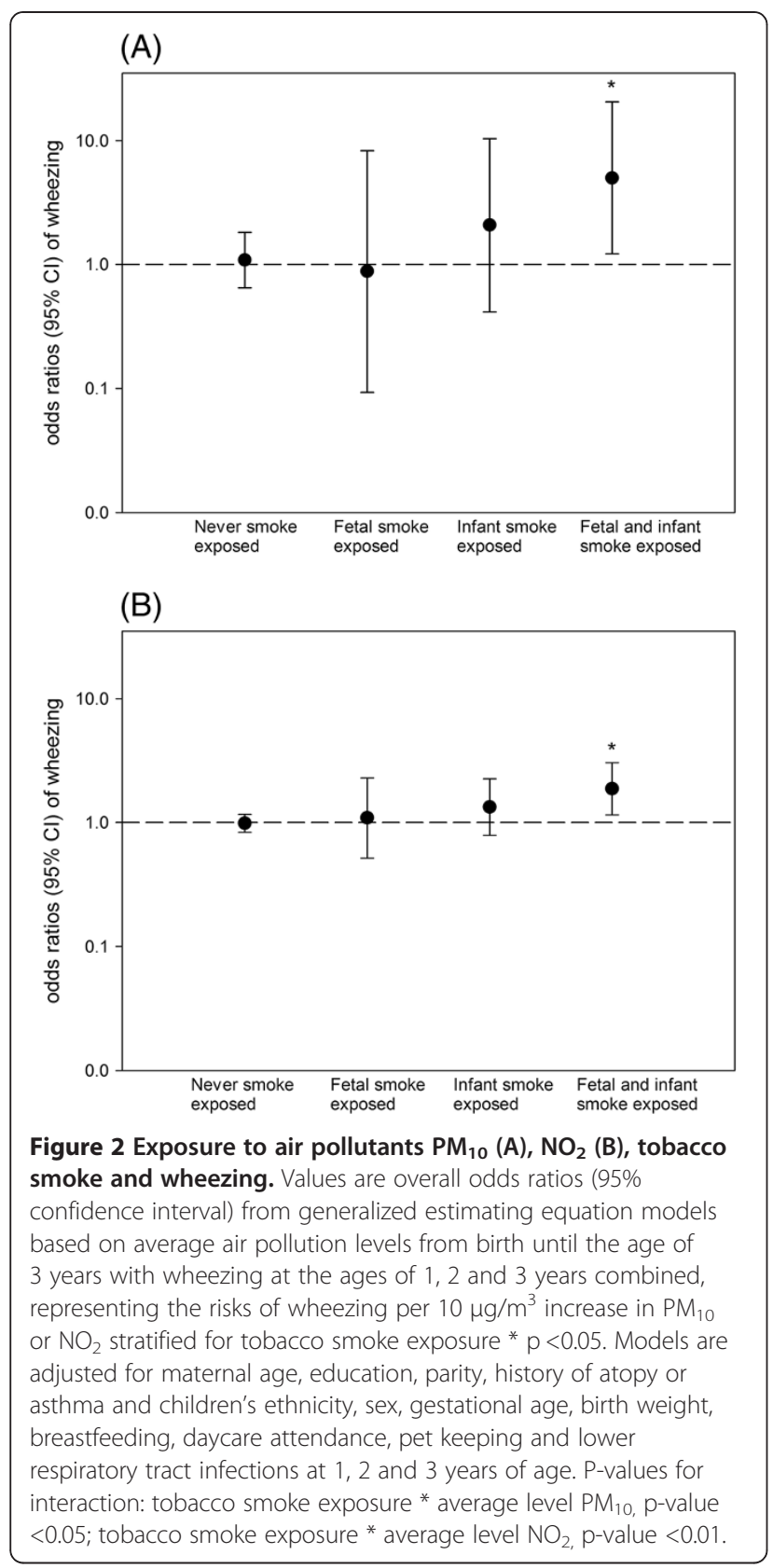

Our results suggest that short term exposure to air pollutants might be important for developing respiratory symptoms, whereas long term exposure to air pollutants might be important in the presence of tobacco smoke exposure. However our results should be considered as hypothesis generating. More studies are needed to explore the combined effects of air pollution and tobacco smoke exposure on the development of respiratory symptoms. Previously, we have reported that children from mothers who smoked continuously during pregnancy and during the first years after pregnancy had increased risks of wheezing in the first years of life [15]. Fetal smoke exposure has been suggested to have a different underlying mechanism in the pathway to wheezing than infant smoke exposure. Fetal smoke exposure may lead to impaired lung development and immunological changes while for infant smoke exposure it includes bronchial hyperreactivity, immunological changes, and direct toxic and irritant effects [35-37]. Increased vulnerability of the airways and lungs to air pollutants might be caused by both fetal and infant smoke exposure via their pathophysiological mechanisms. Among children with infant smoke exposure, we observed a non-significant elevated odds ratio for the associations of air pollution with wheezing. This tendency was not observed in children with only fetal smoke exposure. This might be due to the direct toxic effects of both infant smoke exposure and exposure to air pollutants, which are absent in fetal smoke exposure only [38]. The mechanisms underlying the association of air pollution exposure with wheezing or asthma might also include the induction of airway inflammation and oxidative stress, modification of enzyme functions, disruption of immune responses and increased reactivity to allergens [26,38-40]. Also, respiratory infectious diseases might play a role. However, we did not observe a confounding or modifying effect of respiratory tract infections or associations between air pollutants and respiratory tract infections. Therefore, the associations of air pollution with wheezing in our study are probably not explained by infectious mechanisms. Further studies exploring potential underlying causal mechanisms are needed.

This study was embedded in a population-based prospective design with a large number of subjects being stu died from early life onwards with detailed and frequently prospectively measured information about air pollution levels at the corresponding home-addresses. We adjusted for a large number of confounders and the results did not differ between non-imputed and imputed analysis. Nonresponse at enrolment and lost to follow-up would lead to biased effect estimates if the associations of air pollutants with wheezing would be different between those included and not included in the analyses. Selection bias due to nonparticipation at enrolment in the prenatal phase might have occurred because our study population tends to have a selection towards more affluent and healthy mothers [16] who might have reported less wheezing symptoms and tobacco smoke exposure in their children and have been exposed to lower air pollutant levels [41]. If so, our observed effect estimates would be underestimated. Mothers and children lost to follow-up during the postnatal phase were lower educated ( $67 \%$ vs. $47 \%)$ and smoked more frequently during pregnancy $(21 \%$ vs. $13 \%)$. If children who were lost to follow up would have had more wheezing episodes, this could have led to an underestimation of the observed effect of air pollution and tobacco smoke exposure on wheezing as well. One of the limitations of our study is that we might reflect a selection towards a more healthy population, as the prevalence of preterm birth is lower than average in The Netherlands, 
4.7\% versus $7.7 \%$. A homogeneous population would not affect the observed association of air pollution with wheezing among children exposed and not exposed to tobacco smoke. However such a population might affect the generalizability. The observed effects might be different in a population with more preterm born children. Also, preterm birth could modify the effect between air pollution and wheezing, because airways and lungs of preterm born children might be less developed and therefore might be even more vulnerable to air pollution. Previous studies were limited in their ability to consider the intraurban gradients and temporal variations in air pollutants. However, some had obtained more subject-specific exposure levels [6,7]. A strength of our study is that we were able to consider detailed spatial and temporal contrasts in exposure, in which we were able to take home movements into account. In the first 3 years of life $39.9 \%$ of the children moved at least once. Still there might be misclassification of air pollution assessment. We only calculated exposure levels at home addresses and not at the day care centers or other places where the child may spend days and nights. We assumed that most of the time children until the age of 3 years are near or at their home addresses. Furthermore, other types of indoor or commuting exposure were not taken into account. If any, we expect that this misclassification is non-differential and may have led to an underestimation of the associations [42]. We had no information on smaller particle sizes than $10 \mu \mathrm{m}$. Smaller particles sizes such as $\mathrm{PM}_{2.5}$ might more adversely affect respiratory morbidity than $\mathrm{PM}_{10}$ due to deeper peripheral lung deposition. However, previous studies which measured both $\mathrm{PM}_{10}$ and $\mathrm{PM}_{2.5}$ observed strong correlations between exposure to $\mathrm{PM}_{10}$ and $\mathrm{PM}_{2.5}$ and similar effect sizes of these exposures on childhood asthma or wheezing $[32,43]$. Although assessing smoking habits by questionnaires is valid in epidemiological studies, misclassification may occur due to underreporting [44]. However, the use of biomarkers of tobacco smoke exposure in urine, saliva or blood, or nicotine in indoor air seems not superior to self-report [44-47]. First trimester adverse exposures might be important for fetal lung development [48]. Using data from the same study population, we have previously shown that children do not have an increased risk of preschool wheezing when mothers quitted smoking as soon as they knew they were pregnant [15]. Based on results of our previous study, we categorized no fetal smoke exposure as children who were never exposed to tobacco smoke or were exposed to tobacco smoke until first trimester of pregnancy only [15]. We performed a sensitivity analysis without including fetal smoke exposure during first trimester only, and observed that the effect sizes did not materially change. Still, it might be that our categorization led to some misclassification, with an underestimation of the effect estimates when first trimester only smoking would have comparable effects as continued smoking during pregnancy. The main outcome in our study was self-reported wheezing. This method is widely accepted in epidemiological studies and reliably reflects the prevalence of wheezing in young children [49]. In preschool children a diagnosis of asthma is based on symptoms [50], and objective tests, including lung function or bronchial responsiveness, are difficult to perform in young children and have a very limited if any diagnostic value. Follow up studies at older ages will include more detailed asthma and atopy measurements.

\section{Conclusions}

In conclusion, our results suggest that higher long term exposure levels to traffic-related air pollution lead to higher risks of wheezing in preschool children who were exposed to fetal and infant tobacco smoke. Further studies are needed to explore underlying mechanisms of exposure to air pollutants with and without interaction with tobacco smoke exposure and various types of wheezing and asthma in later life.

\section{Additional file}

Additional file 1: The following supplementary tables are available. Table S1. Cross table of fetal smoke exposure with infant smoke exposure. Table S2. Levels of air pollutant. Table S3. Exposure to air pollutants in previous year, tobacco smoke and wheezing.

\section{Abbreviations}

GEE model: Generalized Estimating Equation model; OR: Odds ratio; 95\% $\mathrm{Cl}$ : 95\% confidence interval; $\mathrm{PM}_{10}$ : Particulate matter $\leq 10 \mu \mathrm{m} ; \mathrm{NO}_{2}$ : Nitrogen dioxide; SD: Standard deviation.

\section{Competing interests}

The authors declare that they have no competing interests.

\section{Authors' contributions}

$A S, Y K, V J, J J$ and LD contributed to the conception and design, acquisition of data, analyses and interpretation of the data, drafted the article, revised it critically for important intellectual content and gave final approval of the version to be published. CG, HR, HM, FP, AH and HM contributed to the conception and design and acquisition of data, revised it critically for important intellectual content and gave final approval of the version to be published.

\section{Acknowledgements}

The Generation R Study is conducted by the Erasmus Medical Center in close collaboration with the School of Law and Faculty of Social Sciences of the Erasmus University Rotterdam, the Municipal Health Service Rotterdam area, Rotterdam, the Rotterdam Homecare Foundation, Rotterdam and the Stichting Trombosedienst and Artsenlaboratorium Rijnmond (STAR), Rotterdam. We thank Sjoerd W. van Ratingen, Peter Y.J. Zandveld, Ernst Meijer, Henk Vos, and Reinier Sterkenburg from TNO Urban Environment and Safety for exposure assessment and data linkage, and the DCMR Environmental Protection Agency Rijnmond (DCMR) for kindly supplying data. We gratefully acknowledge the contribution of participating children and their parents, general practitioners, hospitals, midwives and pharmacies in Rotterdam.

The Generation R Study is made possible by financial support from the Erasmus Medical Center, Rotterdam, the Erasmus University Rotterdam and the Netherlands Organization for Health Research and Development. The researchers are independent from the funders. The study sponsors had no 
role in study design, data analysis, interpretation of data, or writing of this report. Dr Vincent Jaddoe received an additional grant from the Netherlands Organization for Health Research and Development (ZonMw 90700303, 916.10159). Dr Liesbeth Duijts is the recipient of a European Respiratory Society/Marie Curie Joint Research Fellowship - Number MC 1226-2009. The research leading to these results has received funding from the European Respiratory Society and the European Community's Seventh Framework Programme FP7/2007-2013 - Marie Curie Actions under grant agreement RESPIRE, PCOFUND-GA-2008-229571 and from the Seventh Framework Programme, project CHICOS (HEALTH-F2-2009-241504). TNO received funding from The Netherlands Ministry of Housing, Spatial Planning and the Environment (VROM) to support exposure assessments.

\section{Author details}

'The Generation R Study Group, Erasmus Medical Center, Rotterdam, The Netherlands. ${ }^{2}$ Department of Pediatrics, Division of Respiratory Medicine, Erasmus Medical Center, Rotterdam, The Netherlands. ${ }^{3}$ Department of Epidemiology, Erasmus Medical Center, Rotterdam, The Netherlands. ${ }^{4}$ Department of Urban Environment and Safety, Netherlands Organization for Applied Scientific Research (TNO), Delft, The Netherlands. ${ }^{5}$ Department of Pediatrics, Erasmus Medical Center, Rotterdam, The Netherlands. ${ }^{6}$ Department of Pediatric Pulmonology and Allergology, Wilhelmina Children's Hospital, Utrecht, The Netherlands. Department of Public Health, Erasmus Medical Center, Rotterdam, The Netherlands. ${ }^{8}$ Department of Pediatrics, Division of Neonatology, Erasmus Medical Center, Rotterdam, The Netherlands.

Received: 26 June 2012 Accepted: 4 December 2012 Published: 11 December 2012

\section{References}

1. Sarnat JA, Holguin F: Asthma and air quality. Curr Opin Pulm Med 2007, 13(1):63-66

2. Trasande L, Thurston GD: The role of air pollution in asthma and other pediatric morbidities. J Allergy Clin Immunol 2005, 115(4):689-699.

3. Rabinovitch N, Silveira L, Gelfand EW, Strand M: The response of children with asthma to ambient particulate is modified by tobacco smoke exposure. Am J Respir Crit Care Med 2011, 184(12):1350-1357.

4. Andersen ZJ, Bonnelykke K, Hvidberg M, Jensen SS, Ketzel M, Loft S, Sorensen M, Tjonneland A, Overvad K, Raaschou-Nielsen O: Long-term exposure to air pollution and asthma hospitalisations in older adults: a cohort study. Thorax 2012, 67(1):6-11.

5. Rosenlund M, Forastiere F, Porta D, De Sario M, Badaloni C, Perucci CA: Traffic-related air pollution in relation to respiratory symptoms, allergic sensitisation and lung function in schoolchildren. Thorax 2009, 64(7):573-580.

6. Heinrich J, Wichmann HE: Traffic related pollutants in Europe and their effect on allergic disease. Curr Opin Allergy Clin Immunol 2004, 4(5):341-348.

7. Braback L, Forsberg B: Does traffic exhaust contribute to the development of asthma and allergic sensitization in children: findings from recent cohort studies. Environ Health 2009, 8:17.

8. Brauer M, Hoek G, Smit HA, de Jongste JC, Gerritsen J, Postma DS, Kerkhof M, Brunekreef B: Air pollution and development of asthma, allergy and infections in a birth cohort. Eur Respir J 2007, 29(5):879-888.

9. Morgenstern V, Zutavern A, Cyrys J, Brockow I, Gehring U, Koletzko S, Bauer $C P$, Reinhardt D, Wichmann HE, Heinrich J: Respiratory health and individual estimated exposure to traffic-related air pollutants in a cohort of young children. Occup Environ Med 2007, 64(1):8-16.

10. Bateson TF, Schwartz J: Children's response to air pollutants. J Toxicol Environ Health A 2008, 71(3):238-243.

11. Pinkerton KE, Joad JP: Influence of air pollution on respiratory health during perinatal development. Clin Exp Pharmacol Physiol 2006, 33(3):269-272

12. Midodzi WK, Rowe BH, Majaesic CM, Saunders LD, Senthilselvan A: Early life factors associated with incidence of physician-diagnosed asthma in preschool children: results from the Canadian early childhood development cohort study. J Asthma 2010, 47(1):7-13.

13. Brauer M, Hoek G, Van Vliet P, Meliefste K, Fischer PH, Wijga A, Koopman LP, Neijens HJ, Gerritsen J, Kerkhof M, Heinrich J, Bellander T, Brunekreef B: Air pollution from traffic and the development of respiratory infections and asthmatic and allergic symptoms in children. Am J Respir Crit Care Med 2002, 166(8):1092-1098.

14. Gehring U, Wijga AH, Brauer M, Fischer P, de Jongste JC, Kerkhof M, Oldenwening M, Smit HA, Brunekreef B: Traffic-related air pollution and the development of asthma and allergies during the first 8 years of life. Am J Respir Crit Care Med 2010, 181(6):596-603.

15. Duijts L, Jaddoe W, van der Valk RJ, Henderson JA, Hofman A, Raat H, Steegers EA, Moll HA, de Jongste JC: Fetal exposure to maternal and paternal smoking and the risks of wheezing in preschool children: the Generation R Study. Chest 2012, 141(4):876-885.

16. Jaddoe WW, van Duijn $\mathrm{CM}$, Franco $\mathrm{OH}$, van der Heijden AJ, van IJzendoorn $\mathrm{MH}$, de Jongste JC, van der Lugt A, Mackenbach JP, Moll HA, Raat H, Rivadeneira F, Steegers EA, Tiemeier H, Uitterlinden AG, Verhulst FC, Hofman A: The Generation R Study: design and cohort update 2012. Eur J Epidemiol 2012, 27(9):739-756.

17. van den Hooven EH, de Kluizenaar Y, Pierik FH, Hofman A, van Ratingen SW, Zandveld PY, Mackenbach JP, Steegers EA, Miedema HM, Jaddoe WW: Air pollution, blood pressure, and the risk of hypertensive complications during pregnancy: the generation R study. Hypertension 2011, 57(3):406-412

18. Netherlands Ministry of Infrastructure and the Environment: Air Quality Decree 2007 (Regeling beoordeling Luchtkwaliteit 2007): Staatscourant; 2007. Available: http://wetten.overheid.nl/BWBR0022817/ [accessed 12 September 2010].

19. Beelen R, Voogt M, Duyzer J, Zandveld P, Hoek G: Comparison of the performances of land use regression modelling and dispersion modelling in estimating small-scale variations in long-term air pollution concentrations in a Dutch urban area. Atmos Environ 2010, 44:4614-4621.

20. Keuken M, Zandveld P, van den Elshout S, Janssen NAH, Hoek G: Air quality and health impact of PM10 and EC in the city of Rotterdam, the Netherlands in 1985-2008. Atmos Environ 2011, 45:5294-5301.

21. Asher MI, Keil U, Anderson HR, Beasley R, Crane J, Martinez F, Mitchell EA, Pearce N, Sibbald B, Stewart AW, Strachan D, Weiland SK, Williams HC: International Study of Asthma and Allergies in Childhood (ISAAC): rationale and methods. Eur Respir J 1995, 8(3):483-491.

22. Sonnenschein-van der Voort AM, Jaddoe WW, van der Valk RJ, Willemsen SP, Hofman A, Moll HA, de Jongste JC, Duijts L: Duration and exclusiveness of breastfeeding and childhood asthma-related symptoms. Eur Respir J 2012, 39(1):81-89.

23. Spratt M, Carpenter J, Sterne JA, Carlin JB, Heron J, Henderson J, Tilling K: Strategies for multiple imputation in longitudinal studies. Am J Epidemiol 2010, 172(4):478-487.

24. Beunckens C, Sotto C, Molenberghs G: A simulation study comparing weighted estimating equations with multiple imputation based estimating equations for longitudinal binary data. Comput Stat Data Anal 2008, 52(3):1533-1548.

25. Nordling E, Berglind N, Melen E, Emenius G, Hallberg J, Nyberg F, Pershagen G, Svartengren M, Wickman M, Bellander T: Traffic-related air pollution and childhood respiratory symptoms, function and allergies. Epidemiology 2008, 19(3):401-408.

26. Morgenstern V, Zutavern A, Cyrys J, Brockow I, Koletzko S, Kramer U, Behrendt H, Herbarth O, von Berg A, Bauer CP, Wichmann HE, Heinrich J, Group GS, Group LS: Atopic diseases, allergic sensitization, and exposure to traffic-related air pollution in children. Am J Respir Crit Care Med 2008, 177(12):1331-1337.

27. Clark NA, Demers PA, Karr CJ, Koehoorn M, Lencar C, Tamburic L, Brauer M: Effect of early life exposure to air pollution on development of childhood asthma. Environ Health Perspect 2010, 118(2):284-290

28. Carlsten C, Dybuncio A, Becker A, Chan-Yeung M, Brauer M: Traffic-related air pollution and incident asthma in a high-risk birth cohort. Occup Environ Med 2011, 68(4):291-295.

29. Mann JK, Balmes JR, Bruckner TA, Mortimer KM, Margolis HG, Pratt B, Hammond SK, Lurmann FW, Tager IB: Short-term effects of air pollution on wheeze in asthmatic children in Fresno, California. Environ Health Perspect 2010, 118(10):1497-1502.

30. McConnell R, Islam T, Shankardass K, Jerrett M, Lurmann F, Gilliland F, Gauderman J, Avol E, Kunzli N, Yao L, Peters J, Berhane K: Childhood incident asthma and traffic-related air pollution at home and school. Environ Health Perspect 2010, 118(7):1021-1026.

31. Galan I, Tobias A, Banegas JR, Aranguez E: Short-term effects of air pollution on daily asthma emergency room admissions. Eur Respir J 2003, 22(5):802-808. 
32. Iskandar A, Andersen ZJ, Bonnelykke K, Ellermann T, Andersen KK, Bisgaard $\mathrm{H}$ : Coarse and fine particles but not ultrafine particles in urban air trigger hospital admission for asthma in children. Thorax 2012, 67(3):252-257.

33. Penard-Morand C, Raherison C, Charpin D, Kopferschmitt C, Lavaud F, Caillaud D, Annesi-Maesano I: Long-term exposure to close-proximity air pollution and asthma and allergies in urban children. Eur Respir J 2010, 36(1):33-40.

34. Penard-Morand C, Charpin D, Raherison C, Kopferschmitt C, Caillaud D, Lavaud F, Annesi-Maesano I: Long-term exposure to background air pollution related to respiratory and allergic health in schoolchildren. Clin Exp Allergy 2005, 35(10):1279-1287.

35. Wang L, Joad JP, Zhong C, Pinkerton KE: Effects of environmental tobacco smoke exposure on pulmonary immune response in infant monkeys. J Allergy Clin Immunol 2008, 122(2):400-406. 406 e401-405.

36. Wang $L$, Pinkerton KE: Detrimental effects of tobacco smoke exposure during development on postnatal lung function and asthma. Birth Defects Res C Embryo Today 2008, 84(1):54-60.

37. Kum-Nji P, Meloy L, Herrod HG: Environmental tobacco smoke exposure: prevalence and mechanisms of causation of infections in children. Pediatrics 2006, 117(5):1745-1754.

38. Bernstein JA, Alexis N, Barnes C, Bernstein IL, Nel A, Peden D, Diaz-Sanchez D, Tarlo SM, Williams PB: Health effects of air pollution. J Allergy Clin Immunol 2004, 114(5):1116-1123.

39. Li N, Hao M, Phalen RF, Hinds WC, Nel AE: Particulate air pollutants and asthma. A paradigm for the role of oxidative stress in PM-induced adverse health effects. Clin Immunol 2003, 109(3):250-265.

40. Strand V, Rak S, Svartengren M, Bylin G: Nitrogen dioxide exposure enhances asthmatic reaction to inhaled allergen in subjects with asthma. Am J Respir Crit Care Med 1997, 155(3):881-887.

41. Hafkamp-de Groen E, van Rossem L, de Jongste JC, Mohangoo AD, Moll HA, Jaddoe WW, Hofman A, Mackenbach JP, Raat H: The role of prenatal, perinatal and postnatal factors in the explanation of socioeconomic inequalities in preschool asthma symptoms: the Generation R Study. J Epidemiol Community Health 2012, 66(11):1017-1024.

42. Rothman KJ: Epidemiology, an introduction. New York: Oxford University Press; 2002.

43. Oftedal B, Brunekreef B, Nystad W, Madsen C, Walker SE, Nafstad P. Residential outdoor air pollution and lung function in schoolchildren. Epidemiology 2008, 19(1):129-137.

44. Patrick DL, Cheadle A, Thompson DC, Diehr P, Koepsell T, Kinne S: The validity of self-reported smoking: a review and meta-analysis. Am J Public Health 1994, 84(7):1086-1093.

45. Wang X, Tager IB, Van Vunakis H, Speizer FE, Hanrahan JP: Maternal smoking during pregnancy, urine cotinine concentrations, and birth outcomes. A prospective cohort study. Int J Epidemiol 1997, 26(5):978-988.

46. Brunekreef B, Leaderer BP, van Strien R, Oldenwening M, Smit HA, Koopman $L$, Kerkhof M: Using nicotine measurements and parental reports to assess indoor air: the PIAMA birth cohort study. Prevention and Incidence of Asthma and Mite Allergy. Epidemiology 2000, 11(3):350-352.

47. Margolis PA, Keyes LL, Greenberg RA, Bauman KE, LaVange LM: Urinary cotinine and parent history (questionnaire) as indicators of passive smoking and predictors of lower respiratory illness in infants. Pediatr Pulmonol 1997, 23(6):417-423.

48. Mook-Kanamori DO, Steegers EA, Eilers PH, Raat H, Hofman A, Jaddoe WW Risk factors and outcomes associated with first-trimester fetal growth restriction. JAMA 2010, 303(6):527-534.

49. Jenkins MA, Clarke JR, Carlin JB, Robertson CF, Hopper JL, Dalton MF, Holst DP, Choi K, Giles GG: Validation of questionnaire and bronchial hyperresponsiveness against respiratory physician assessment in the diagnosis of asthma. Int J Epidemiol 1996, 25(3):609-616.

50. Edwards CA, Osman LM, Godden DJ, Douglas JG: Wheezy bronchitis in childhood: a distinct clinical entity with lifelong significance? Chest 2003, 124(1):18-24.

doi:10.1186/1476-069X-11-91

Cite this article as: Sonnenschein-van der Voort et al: Air pollution, fetal and infant tobacco smoke exposure, and wheezing in preschool children: a population-based prospective birth cohort. Environmental Health 2012 11:91.

\section{Submit your next manuscript to BioMed Central and take full advantage of:}

- Convenient online submission

- Thorough peer review

- No space constraints or color figure charges

- Immediate publication on acceptance

- Inclusion in PubMed, CAS, Scopus and Google Scholar

- Research which is freely available for redistribution 